\title{
A novel emulsion fuel containing aqueous nano cerium oxide additive in diesel-biodiesel blends to improve diesel engines performance and reduce exhaust emissions: part I - experimental analysis
}

\begin{abstract}
Improving fuel combustion in engines and consequently reducing environmentallyunfavorable emissions is of prominent importance in addressing some of the main challenges of the current century, i.e., global warming and climate change. Fuel additives are considered as efficient way for improving fuel properties and to diminish engine emissions. In line with this, the present research was focused on the simultaneous application of water $(3,5$, and $7 \mathrm{wt} \%$ ) and cerium oxide nano particles (90 ppm) as metal-based additive into biodiesel/diesel fuel blend (B5) and their impacts on the performance and emission characteristics of a single cylinder four stroke diesel engine were investigated. The findings revealed that the aqueous nano-emulsion of cerium oxide improved the overall combustion quality. More specifically, the brake specific fuel consumption (bsfc) of B5 containing 3\% water and $90 \mathrm{ppm}$ cerium oxide $(\mathrm{B} 5 \mathrm{~W} 3 \mathrm{~m})$ was measured $5 \%$ and $16 \%$ lower than those of neat B5 and neat B5 containing 3\% water (B5W3), respectively. Moreover, the B5W3m fuel blend increased brake thermal efficiency (bte) by over 23 and $11 \%$ compared with B5W3 and B5, respectively. B5W3m also considerably reduced CO, $\mathrm{HC}$, and NOx emissions by 51, 45, and $27 \%$ compared with B5W3. To the best of our knowledge, this is the first report exploring the impacts of low-level water containing cerium oxide in B5 on engine performance and emission characteristics.
\end{abstract}

Keyword: Biodiesel; Water; Metal-based additive; Diesel engine; Emission; Performance 